\title{
Formation of Trihalomethanes during Seawater Chlorination
}

\author{
Ahmed Abdel-Wahab ${ }^{1}$, Ahmed Khodary ${ }^{1}$, Nasr Bensalah ${ }^{2}$ \\ ${ }^{1}$ Chemical Engineering Program, Texas A\&M University at Qatar, Doha, Qatar; ${ }^{2}$ Faculty of Sciences of Gabes, University of Gabes, \\ Gabes, Tunisia. \\ Email: ahmed.abdel-wahab@qatar.tamu.edu, nasr.bensalah@issatgnb.rnu.tn
}

Received July $23^{\text {rd }}, 2010$; revised June $22^{\text {nd }}, 2010$; accepted June $26^{\text {th }}, 2010$

\begin{abstract}
The use of seawater for industrial cooling is a vital technology that poses some of the most profound environmental impact on the water quality in the Arabian Gulf. Biocide (chlorine) is added to the seawater to control biofouling of the cooling system. This added chlorine reacts with bromide and other chemicals naturally exist in the water to form a wide range of oxidants. Regrettably, reactions between the residual oxidants and natural organic matter in the water lead to formation of toxic halogenated organic compounds that have detrimental effects on the environment when they are discharged into the Gulf. This paper describes the formation of trihalomethanes (THMs) in seawater cooling systems. Results of kinetic experiments have shown that concentrations of THMs increased rapidly with time during the first half hour. Chlorination of seawater has shown significant increase in total THMs (TTHMs) and in bromoform concentrations. Rapid decrease of UV absorbance at $254 \mathrm{~nm}$ was also observed during seawater chlorination which is indicative of natural organic matter degradation into small organic molecules including THMs and other by-products. The increase in chlorine dose was accompanied with an increase in TTHMs and bromoform concentrations. Linear relationships between total chlorine concentration and both final TTHMs and bromoform concentrations were established. First order exponential decay and exponential associate functions were developed to correlate chlorine dose with formed THMs.
\end{abstract}

Keywords: Chlorination by-Products, Seawater Cooling, Biocides, Trihalomethane, Bromoform

\section{Introduction}

The use of seawater in industrial cooling is a common practice in many parts of the world that have limited fresh-water resources. One of the primary operational problems of using seawater in cooling is biofouling. Biofouling can result from growth of microorganisms on surfaces where they form biofilms or from the growth of macro-organisms such as clams. Biofilms tend to stick to heat-exchange surfaces, thereby significantly reducing heat-transfer coefficients. In some cases, excessive biofouling can lead to plugging of heat exchangers. There are several techniques for preventing biofouling of both types, but application of chlorine-based biocide is most common.

Chlorine is added directly to the seawater to control biofouling of the cooling system. The added chlorine reacts with bromide and other compounds in the water to produce a wide range of chemical oxidants. These include conversion of bromide ion to hypobromous acid and other reactive forms of bromine. These brominated products are the active forms of biocide in seawater systems and their relative concentrations change on time scales from fractions of seconds to days. Understanding their behavior is critical to insuring effective control of biofouling within the plant and minimizing environmental impacts outside the plant. Additionally, the brominated residual biocide can react with natural organic matter in the seawater to form a number of halogenated organic compounds that are toxic to aquatic life as well as humans. Brominated forms of biocide are much more effective in producing halogenated organics than chlorine [1], but have not been studied as extensively.

Understanding the reaction scheme of chlorine, brominated products and natural organic matter is critical to optimizing performance of biofouling control systems while minimizing impacts to the aquatic environment and to human health. Studies by Shams et al. [2] on Umm Al Nar seawater desalination plant in Abu Dhabi showed that bromoform represented $95 \%$ of the trihalomethanes 
(THMs) that were formed. Ali and Riley [3] reported that THMs concentrations as high as $90 \mu \mathrm{g} / \mathrm{L}$ were observed in the vicinity of discharges from combined power/desalination plants in Kuwait. Many other reports are available on the production of halogenated organics in freshwater systems such as water treatment plants and water distribution systems [4-11]. However, limited data are available on biocides chemistry and their reaction by-products in seawater.

The purpose of this paper is to study the formation of trihalomethanes in seawater and to quantitatively predict changes in concentrations of biocides and reaction products in cooling water. This will provide the basis for developing a full kinetic model to describe the biocide chemistry in seawater and for developing a simulation tool to determine the fate and transport of biocides and their reaction products in the environment.

\section{Materials and Methods}

\subsection{Chemicals}

Seawater samples were collected in October 2008 from side tap of Doha costal sea at Qatar. Samples were placed in amber glass bottles and chlorinated immediately after collection whenever possible; otherwise, they were kept in the refrigerator at $4^{\circ} \mathrm{C}$. Analytical standard mix solutions of halogenated volatiles (2000 ppb each in acetone) were of analytical grade (purity 99\%). The THMs contained in the standard solution were chloroform, bromoform, bromodichloromethane (BDCM), and dibromochloromethane (DBCM). Standard solutions (1, 5, 10, 20, 50 and $100 \mathrm{ppb}$ ) were prepared from analytical standard mix solutions by dilution in acetone for calibration method. Organic solvents used in dilution and extraction were high purity grade. All chemicals used in the experiments were prepared from analytical grade chemical reagents without any further purification.

\subsection{Kinetic Experiments}

Seawater chlorination was performed using sodium hypochlorite $(\mathrm{NaOCl})$ solution $(12 \%)$ as the chlorine source. Four different doses of chlorine were studied (1, 2, 3 and $4 \mathrm{ppm}$ as $\mathrm{Cl}_{2}$ ). The reactors were $60 \mathrm{ml}$ borosilicate glass bottles with TFE-faced septa and polypropylene screw caps. The vials were carefully filled so that trapping of air bubbles inside was prevented (headspace free) and possible volatilization of THMs was evaded. Then they were allowed to react at room temperature $\left(25^{\circ} \mathrm{C}\right)$ and were analyzed after reaction times of $0.0,0.5,1,6,18,24$, 48, 72, 96, 120 and 168 hours. Sodium thiosulfate was instantaneously added to each sample taken at a desired time during experiment to quench chlorine and stop any further formation of halogenated organic components.
These samples were then analyzed for free chlorine, total chlorine, total organic carbon (TOC), dissolved organic carbon (DOC), $\mathrm{pH}$ and THMs concentrations.

\subsection{Analytical Procedures}

TOC and DOC concentrations were analyzed using a Skalar TOC/TN analyzer. pH measurement was performed using a VWR SympHony pH-meter. UV absorbance measurements were carried out for raw seawater as well as for chlorinated seawater samples at $254 \mathrm{~nm}$ by use of a Perkin-Elmer (Lambda 25) UV-visible spectrophotometer with $1 \mathrm{~cm}$ quartz cells. Bromide ions concentration was determined according to standard method phenol red colorimetric method [12]. Free and total chlorine were measured according to DPD colorimetric method [12]. THMs were analyzed using gas chromatography (GC) equipped with micro-electron capture detector ( $\mu$-ECD). The gas chromatograph Agilent technologies 7890A GC system equipped with a capillary fused silica DB- 1 column $(30 \mathrm{~m}$ length $\times 0.32 \mathrm{~mm}$ id $\times 0.25 \mathrm{~mm}$ film thickness) was used. Injections were made in splitless mode, with helium as carrier gas (flow rate $1.6 \mathrm{~mL} \mathrm{~min}^{-1}$ ) and auto-sampler. For THMs analysis, $35 \mathrm{~mL}$ were taken from each vial and extracted with $2 \mathrm{~mL}$ methyl-tert-butyl ether (MTBE). $1 \mu \mathrm{L}$ of the extract was then injected into the GC system. Temperature was programmed from $35^{\circ} \mathrm{C}$ to $120^{\circ} \mathrm{C}$ as follows: an initial hold of nine minutes at $35^{\circ} \mathrm{C}$, increase from $35^{\circ} \mathrm{C}$ to $40^{\circ} \mathrm{C}$ at $1{ }^{\circ} \mathrm{C} \mathrm{mn}$, a hold of 3 minutes at $40^{\circ} \mathrm{C}$, temperature increase from $40^{\circ} \mathrm{C}$ to $120^{\circ} \mathrm{C}$ at $6^{\circ} \mathrm{C} \mathrm{mn}{ }^{-1}$ with a final hold time of 3 minutes. Total THMs concentrations (TTHMs) were calculated (in ppb as $\mathrm{CHCl}_{3}$ ) from THMs concentrations (in pbb) using the following Equation (1):

$$
\begin{aligned}
& \text { TTHMs }=\mathrm{CHCl}_{3}+0.728 *[\mathrm{BDCM}] \\
& +0.574 *[\mathrm{DBCM}]+0.472 *\left[\mathrm{CHBr}_{3}\right]
\end{aligned}
$$

\section{Results and Discussion}

Table 1 illustrates concentrations TOC, DOC, UV-absorbance and THMs in seawater collected from Arabian Gulf in Qatar before any treatment. As it can be seen, raw seawater contains residual amounts of free chlorine (0.14 ppm), $0.35 \mathrm{ppm}$ total oxidants and $7 \mathrm{ppm}$ TOC. This could be due to the discharge of large quantities of chlorinated treated domestic wastewaters into the Arabian Gulf near Doha. Organic carbon content was mostly dissolved organic matter as revealed by the little difference between TOC and DOC concentrations. As it can be also observed, 1 ppb TTHMs is monitored in raw seawater with bromoform as the main halogenated product present. Little amounts of bromodichloromethane (DBCM) and dibromochloromethane (DBCM) were also detected, 
Table 1. Physic-chemical analyses of unchlorinated seawater collected from Arabian Gulf in Doha-Qatar.

\begin{tabular}{cc}
\hline Parameters & Values \\
\hline $\mathrm{pH}$ & 8.2 \\
$\mathrm{TOC}\left(\mathrm{mg} \mathrm{L}^{-1}\right)$ & 6.6 \\
$\mathrm{DOC}\left(\mathrm{mg} \mathrm{L}^{-1}\right)$ & 5.8 \\
$\mathrm{UV}$ absorbance at $254 \mathrm{~nm}$ & 2.0 \\
Br $^{-}\left(\mathrm{mg} \mathrm{L}^{-1}\right)$ & 64.0 \\
Bromoform (ppb) & 1.71 \\
TTHMs (ppb) & 1.03 \\
\hline
\end{tabular}

but no chloroform was detected in the collected fresh seawater.

The formation of brominated THMS is due to the high concentration of bromide present in the Arabian Gulf seawater ( $\sim 64 \mathrm{ppm})$ [2]. This results in the conversion of hypochlorous acid to hypobromous acid as shown in Equation 2 below.

$$
\mathrm{HOCl}+\mathrm{Br}^{-} \rightleftarrows \mathrm{HOBr}+\mathrm{Cl}^{-}
$$

The formed $\mathrm{HBrO}$ and other forms of brominated oxidants generated from bromide oxidation react with organic precursors present in the water and form the brominated methanes.

In addition, high UV absorbance at $254 \mathrm{~nm}$ was measured (about 2.00) indicating that Doha seawater contains significant amount of aromatic compounds mainly resulting from natural distribution of humic acids. The presence of humic substances favors THMs formation from their reactions with halogenated oxidants.

The preservation of seawater at room temperature leads to important changes in organic and inorganic content in Doha seawater. Rapid decrease of free and total chlorine is observed, ending to their total disappearance after half hour from collecting seawater samples. The disappearance of chlorine was accompanied with a rapid decrease in UV absorbance at $254 \mathrm{~nm}$, a slight decrease in organic carbon concentration and a large increase in TTTMs content. The decrease of TOC from $6.64 \mathrm{ppm}$ to $5.02 \mathrm{ppm}$ indicates that only $25 \%$ of organic carbon is transformed into $\mathrm{CO}_{2}, \mathrm{H}_{2} \mathrm{O}$ and other inorganic ions. UV absorbance at $254 \mathrm{~nm}$ decreased from 1.99 to 0.265 up to 120 hours which is indicative of natural organic matter degradation to small organic molecules without TOC removal, but only small fraction of organic carbon is transformed into trihalogenated methanes.

TTHMs concentration increased with time up to 120 hours to reach $23 \mathrm{ppb}$, before it became invariant for 168 hours. Particularly, chloroform $\left(\mathrm{CHCl}_{3}\right)$ and bromodi- chloromethane $\left(\mathrm{CHCl}_{2} \mathrm{Br}\right)$ became the major halogenated components in seawater, while, in fresh seawater, $\mathrm{CHCl}_{3}$ was not detected and only traces of BDCM were monitored. Chloroform was detected, for the first time, after 18 hours seawater preservation at room temperature. Chloroform concentration was found to increase with time up to 120 hours before it leveled off and remained constant for 168 hours. Furthermore, a significant increase with time of bromodichloromethane concentration was observed to reach $4.25 \mathrm{ppb}$ after 168 hours. Results indicate also that bromoform concentration increased with time to reach a maximum after 6 hours before it slightly decreased with time up to 18 hours and ended to be constant. The evolution of dibromochloromethane concentration was markedly different from other THMs since it was quickly disappeared during seawater preservation. The evolution of THMs with time can be explained by the nature of residual chlorine present in seawater. Less than $40 \%$ of total chlorine contained in seawater was free chlorine. As it is largely reported, free chlorine mainly reacts with bromide to form bromine that oxidizes natural organic matter leading to an increase in bromoform concentration. In contrast, other forms of chlorine such as chloroamines react directly with natural organic matter to form chlorinated methanes which is in agreement with the increase of chloroform and BDCM content and the disappearance of DBCM.

\subsection{THMs Formation during Chlorination of Doha Seawater}

Figure 1 shows the evolution of free and total chlorine concentrations as function of time during chlorination of seawater with $1 \mathrm{ppm}$ chlorine dose.

As it can be seen, the two concentrations decreased continuously with time. Free chlorine disappeared from solution after less than 48 hours, while at this time $80 \%$ total chlorine is consumed. The disappearance of chlorine from seawater is indicative of consumption of high oxidation state chlorine element during redox reactions including oxidation of bromide to bromine and formation of chlorination by-products from natural organic matter degradation. It is generally reported that seawater contains high amounts of bromide which is rapidly transformed by chlorine to hypobromous acid and other forms of bromine. These compounds are well known to be more powerful oxidant than chlorine species transforming organic matter mainly to brominated by-products.

The evolution with time of TOC and DOC concentrations and UV absorbance during chlorination of seawater samples is shown in Figure 2.

During the first half hour of the treatment, a rapid decrease in the UV absorbance at $254 \mathrm{~nm}$ was observed and 


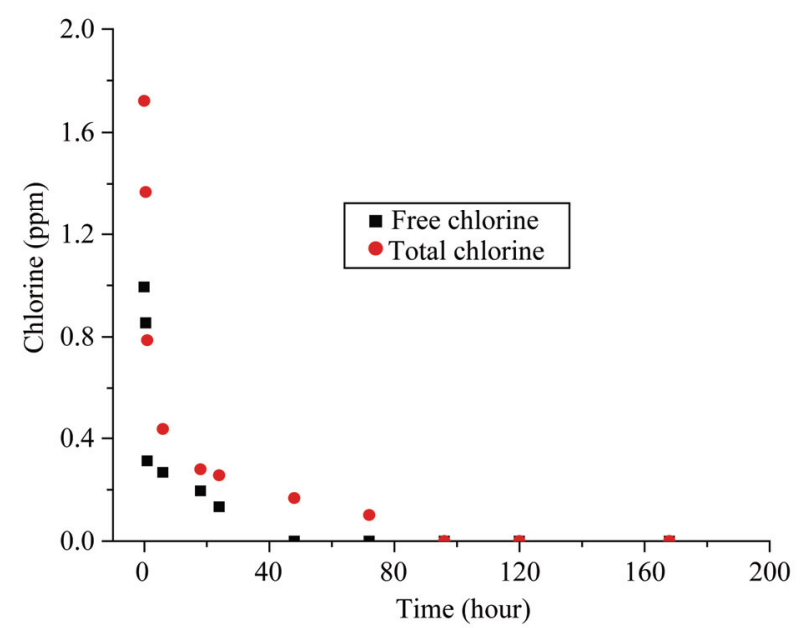

Figure 1. Evolution with time of free and total chlorine concentrations during Doha seawater chlorination with 1 ppm chlorine at room temperature $\left(25^{\circ} \mathrm{C}\right)$ and natural $\mathrm{pH}$ $(\mathrm{pH}=\mathbf{8 . 3})$.

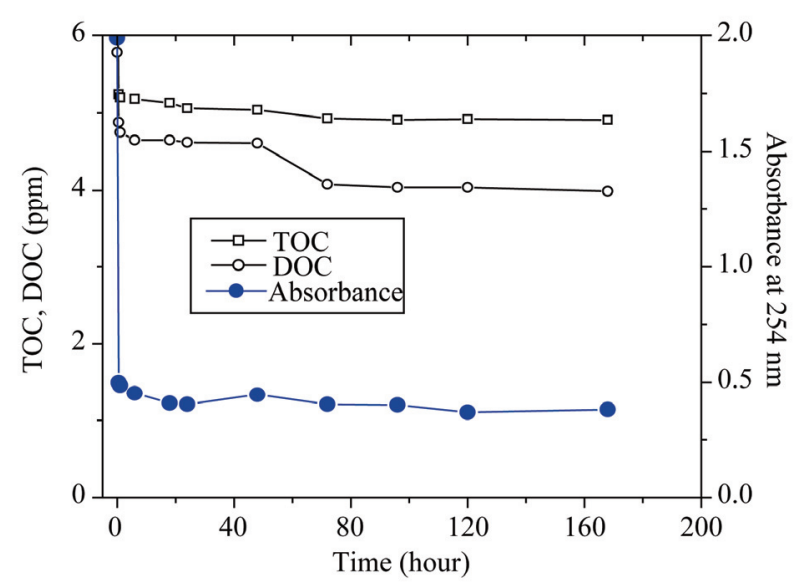

Figure 2. Evolution with time of TOC, DOC and UV absorbance at $254 \mathrm{~nm}$ during Doha seawater chlorination with $1 \mathrm{ppm}$ chlorine at room temperature $\left(25^{\circ} \mathrm{C}\right)$ and natural $\mathrm{pH}$ $(\mathrm{pH}=\mathbf{8 . 3})$.

then it hung about 0.4-0.5 after 6 hours. TOC and DOC undergone a little decrease at the beginning of seawater chlorination up to 72 hours and they became invariant for the rest of experiment. These results are indicative of the degradation of the natural organic matter during Doha seawater chlorination to form several chlorination byproducts including THMs, haloacetic acids and other volatile halogenated compounds (haloacetonitriles and haloketones).

Chlorination of fresh seawater with $1 \mathrm{ppm}$ chlorine dose has shown a significant increase in TTHMs concentration. Figure 3 presents the evolution with time of THMs concentrations during chlorination of Doha seawater with $1 \mathrm{ppm}$ chlorine dose. As it can be seen, TTHMs

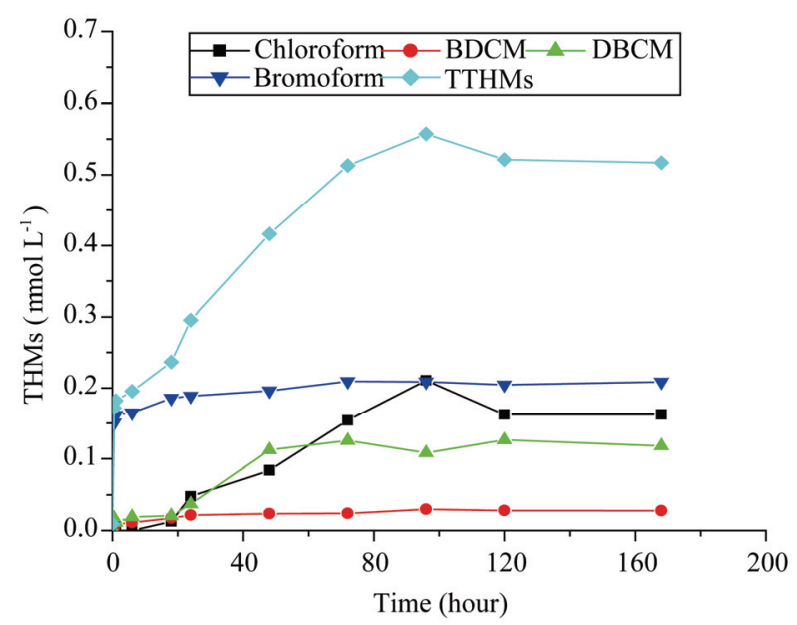

Figure 3. Evolution with time of THMs concentrations during Doha seawater chlorination with $1 \mathrm{ppm}$ chlorine at room temperature $\left(25^{\circ} \mathrm{C}\right)$ and natural $\mathrm{pH}(\mathrm{pH}=8.3)$.

concentration increased rapidly with time and reached a plateau at $0.5 \mu \mathrm{mol} \mathrm{L}^{-1}(50 \mathrm{ppb})$ after 72 hours chlorination with only $1 \mathrm{ppm}$ chlorine dose which indicates that a part of the natural organic matter contained in seawater was transformed into halogenated by-products. Bromoform, chloroform, DBCM and BDCM were identified as chlorination by-products in Doha seawater with molecular fractions of $40.3,31.4,22.8$ and $5.4 \%$, respectively.

THMs concentrations increased with time during chlorination, but in different manner. Bromoform concentration has shown the most rapid increase to remaining constant at $0.2 \mu \mathrm{mol} \mathrm{L} \mathrm{L}^{-1}$ after half hour. The increase with time in BDCM and DBCM concentrations is similar, but less rapid than that of bromoform concentration since they reached highest concentrations after 18 and 72 hours from the beginning of experiments. Chloroform concentration evolution presented different pattern than other THMs; chloroform is not detectable at the beginning, but after 18 hours chlorination its concentration increased with time up to 120 hours and then leveled off and remained constant for the rest of experiment. It is remarkable that at the end of experiments $\mathrm{CHBr}_{3}$ and $\mathrm{CHCl}_{3}$ have comparable molar concentrations which are indicative of a competitive formation of chlorinated and brominated chlorination by-products from natural organic matter oxidation contained in Doha seawater by $1 \mathrm{ppm}$ chlorine dose.

Regarding these results, it can be perceived that both THMs concentrations and their speciation were noticeably different from those recently reported in literature concerning seawater chlorination by-products. Fabbricino and Korshin [13], reported that THMs concentration depends largely on seawater quality and TOC content, but in all cases they found that bromoform was the predomi- 
nant trihalomethane detected during chlorination with $1 \mathrm{ppm}$ chlorine dose of Pacific Ocean and Seattle (Washington State, USA) coastal seawaters. Fayad and Iqbal [14] have shown that the nature of chlorination by-products resulting from seawater treatment depend on the chemical structure of humic materials present in seawater. They also identified bromoform and DBCM as main chlorination by-products during treatment with chlorine doses 0.8-1.6 ppm of Halfmoon Bay beach seawater in Saudi Arabia. According to the results obtained here and those reported in literature [4-14], it can be concluded that THMs levels formed during seawater chlorination (with low chlorine dose) depend on different parameters including seawater location (costal, Ocean and depth), TOC concentration, organic matter chemical structure,

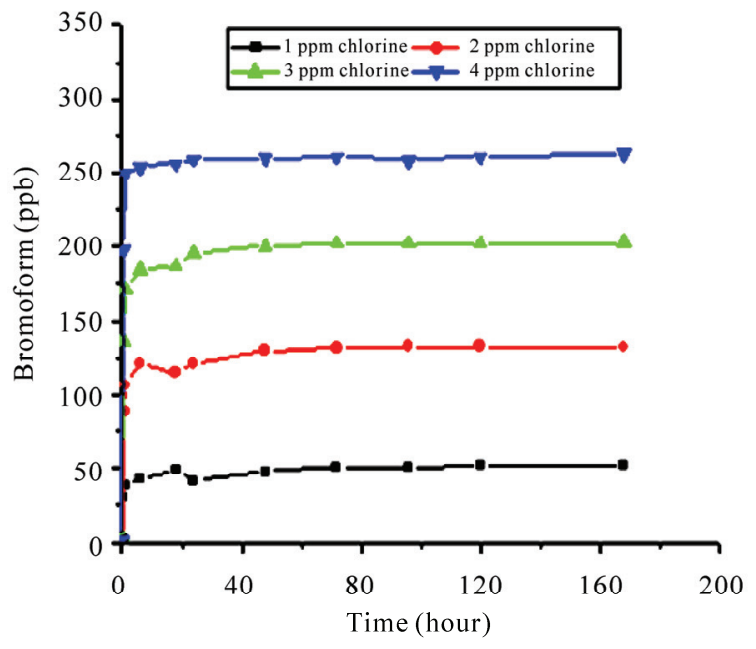

(a)

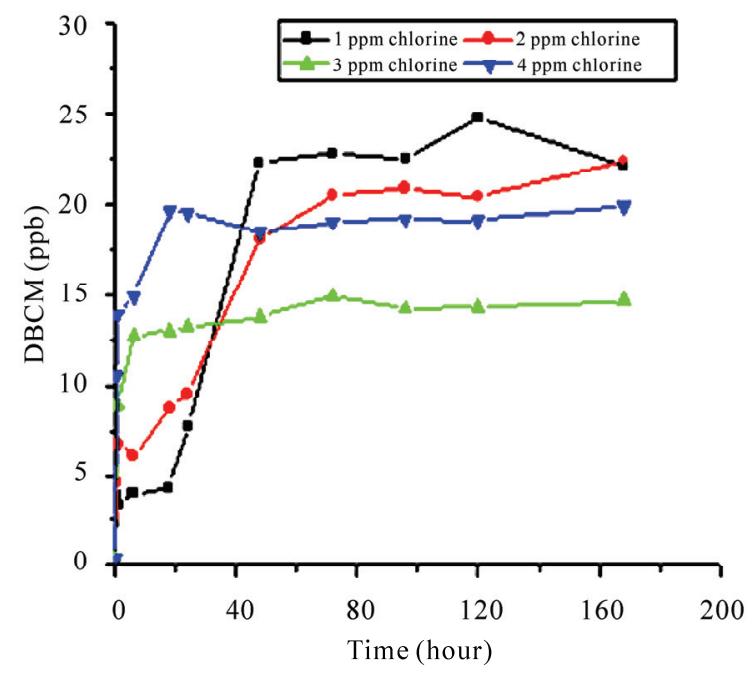

(c) and bromide concentration.

The influence of chlorine dose on the evolution of THMs concentrations during chlorination of Doha seawater is illustrated in Figure 4. As it can be observed, only bromoform concentration and predominance were largely affected by chlorine dose change. Increasing chlorine dose from $1 \mathrm{ppm}$ to $4 \mathrm{ppm}$, bromoform concentration increased also from $50 \mathrm{ppb}$ to $260 \mathrm{ppb}$ and its molar fraction in TTHMs passed from $4.6 \%$ with residual chlorine to $75.4 \%$ with 4 ppm chlorine (see Table 2).

As it can be also seen, seawater chlorination had no significant influence on concentrations of chloroform, BDCM and DBCM, but their molar fractions were largely decreased. These observations show that the contribution of bromine in the formation of THMs in chlorinated

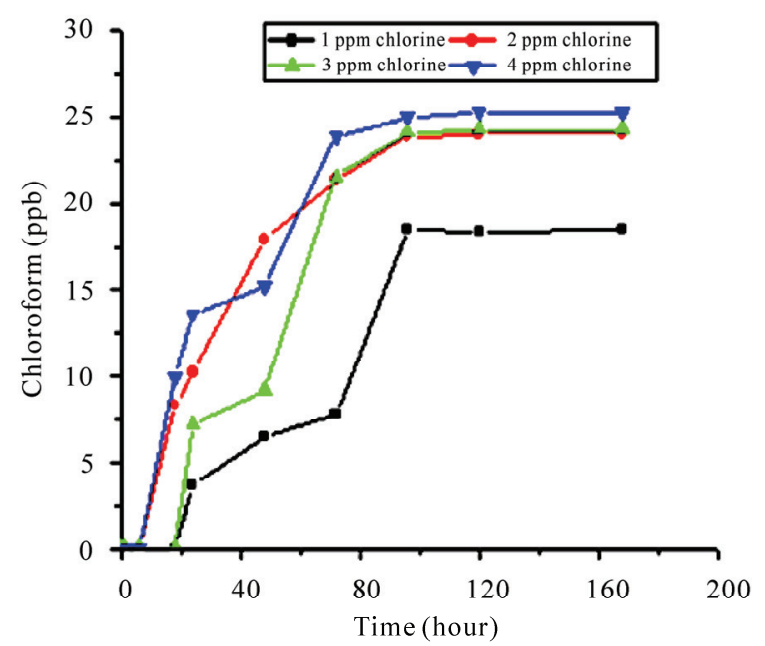

(b)

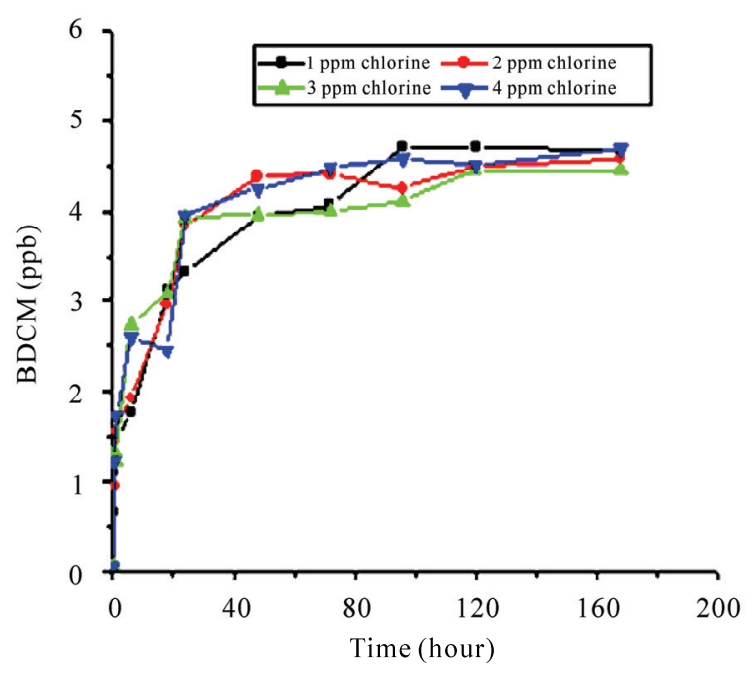

(d)

Figure 4. Influence of chlorine dose on the evolution with time of THMs concentrations during Doha seawater chlorination at room temperature $\left(25^{\circ} \mathrm{C}\right)$ and natural $\mathrm{pH}(\mathrm{pH}=8.3)$; (a) bromoform; (b) chloroform; (c) DBCM and (d) BDCM. 
Table 2. Evolution of THMs molar fraction in TTHMs as function of chlorine dose after 168 hours chlorination of Doha coastal seawater at room temperature $\left(25^{\circ} \mathrm{C}\right)$ and natural $\mathrm{pH}$ (initial $\mathrm{pH}=\mathbf{8 . 3}$ ).

\begin{tabular}{ccccc}
\hline Chlorine dose & Chloroform & BDCM & DBCM & Bromoform \\
\hline Residual chlorine & $82.8 \%$ & $12.6 \%$ & 0 & $4.6 \%$ \\
1 ppm chlorine & 30.2 & 5.25 & $22.0 \%$ & $42.6 \%$ \\
2 ppm chlorine & $22.2 \%$ & $3.6 \%$ & $12.4 \%$ & $61.8 \%$ \\
3 ppm chlorine & $18.6 \%$ & $2.5 \%$ & $5.7 \%$ & $73.2 \%$ \\
4 ppm chlorine & $15.7 \%$ & $2.0 \%$ & $6.9 \%$ & $75.4 \%$ \\
\hline
\end{tabular}

Doha seawater is more important at high chlorine doses. In fact, chlorine reacts immediately with bromide ions to form hypobromous acid and other bromine forms; more the chlorine dose is high, more reaction 2 is shifted to right.

The levels of brominated oxidants increase with chlorine dose and then large amounts of brominated THMs, mainly bromoform, can be measured. Furthermore, Figure 5 shows the evolution of TTHMs concentration as function of both time and chlorine dose. It appears that chlorine level had an important influence on kinetics and yields of THMs formation. The increase of chlorine dose from $1 \mathrm{ppm}$ to $4 \mathrm{ppm}$ has led to an increase of TTHMs concentration from about $60 \mathrm{ppb}$ to $165 \mathrm{ppb}$. As it can be seen also from Figure 5, THMs formation rate was initially rapid matching with the rapid consumption of chlorine, followed by a declining rate. Maximum TTHMs concentration was reached as faster as chlorine concentration is high. These results show that the increase of chlorine dose leads to a significant increase in TTHMs concentration.

At high chlorine doses, bromoform becomes the main trihalomethane component formed in chlorinated Doha seawater. Similar results were stated by several studies regarding THMs formation during seawater chlorination, and it was commonly reported that bromoform was the predominant THM identified during seawater chlorination with $1 \mathrm{ppm}$ chlorine dose. In contrast, with $1 \mathrm{ppm}$ chlorine dose, no such predominance was seen for Doha seawater, although the bromide concentration was likely to be somewhat higher than in other costal seawaters.

Figure 6 shows that final TTHMs and bromoform concentrations (monitored after 168 hours chlorination) increased linearly with initial total chlorine concentration measured at the beginning of seawater chlorination. It can be deduced from this figure that the evolution of final TTHMs and bromoform concentrations could be estimated using linear functions of initial total chlorine concentration $\left(\mathrm{C}_{\text {tot }}^{0}\right)$, as given by Equations (3) and (4):

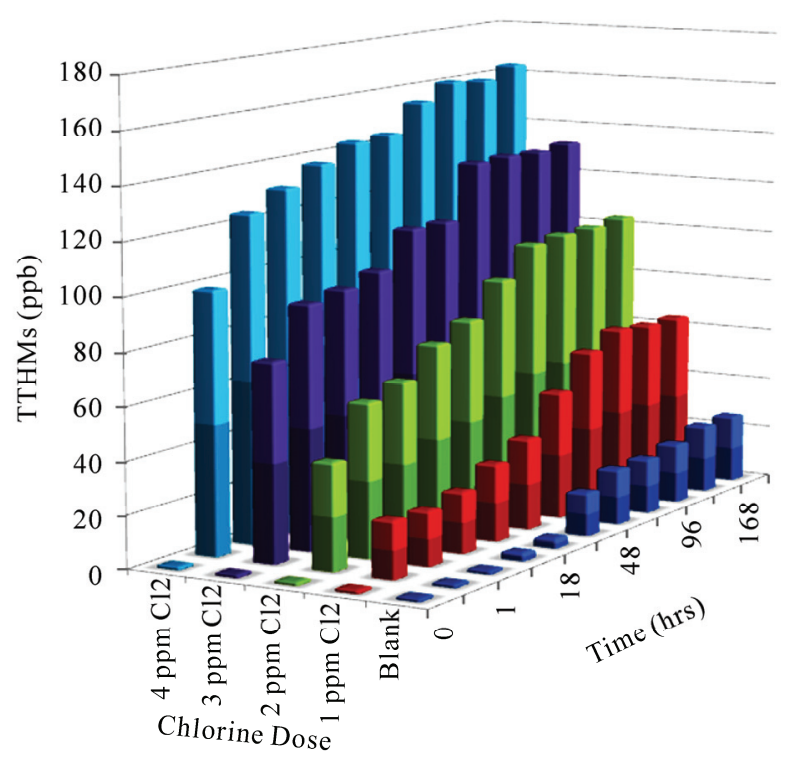

Figure 5. Evolution of TTHMs concentration as function of time and chlorine dose during Doha seawater chlorination at room temperature $\left(25^{\circ} \mathrm{C}\right)$ and natural $\mathrm{pH}(\mathrm{pH}=8.3)$.

$$
\begin{aligned}
& {[\operatorname{TTHMs}(\mathrm{ppb})]=10.3+31.8 \times \mathrm{C}_{\text {tot }}^{0}\left(\mathrm{R}^{2}=0.99038\right)} \\
& {\left[\mathrm{CHBr}_{3}(\mathrm{ppb})\right]=-32.4+60.4 \times \mathrm{C}_{\text {tot }}^{0}\left(\mathrm{R}^{2}=0.98823\right)}
\end{aligned}
$$

These observations are interesting and practical to control TTHMs and bromoform concentrations (under regulation limits) during Doha seawater chlorination and then avoid their hazardous effects on marine environment. These results imply also that Doha seawater chlorination with low chlorine doses is preferable to preventing biofouling, controlling THMs formation and maintaining TTHMs and bromoform levels lower than maximum contaminant limits (MCL) [10].

\subsection{Chlorine Decay and TTHMs Formation Kinetics, Curve-Fitting and Parameters}

Numerous researches proposed mathematical models to predict chlorine decay and THMs formation in chlorinated natural and drinking waters [13-18]. Especially, chlorine decay was evaluated with first-order decay model [19], the EPA model [19], Hass and Karra model [20] and Clark's model [21]. However, only limited researches have been focused on modeling chlorine decay and THMs formation in chlorinated seawaters. In our work, OriginLab (Origin version 6.1) software was used to predict the evolution with time of total chlorine, free chlorine, TTHMs and bromoform concentrations.

For each chlorine level, a parallel exponential first order decay curve was fitted to experimental data corresponding to total chlorine $\left(\mathrm{C}_{\text {tot }}\right)$ and free chlorine $\left(\mathrm{C}_{\text {Free }}\right)$ concentrations evolution with time, according to the fol- 


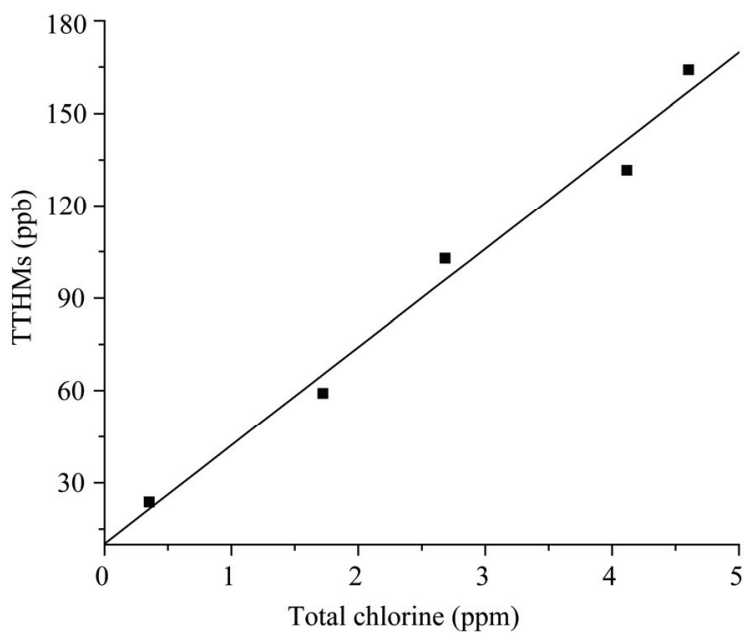

(a)

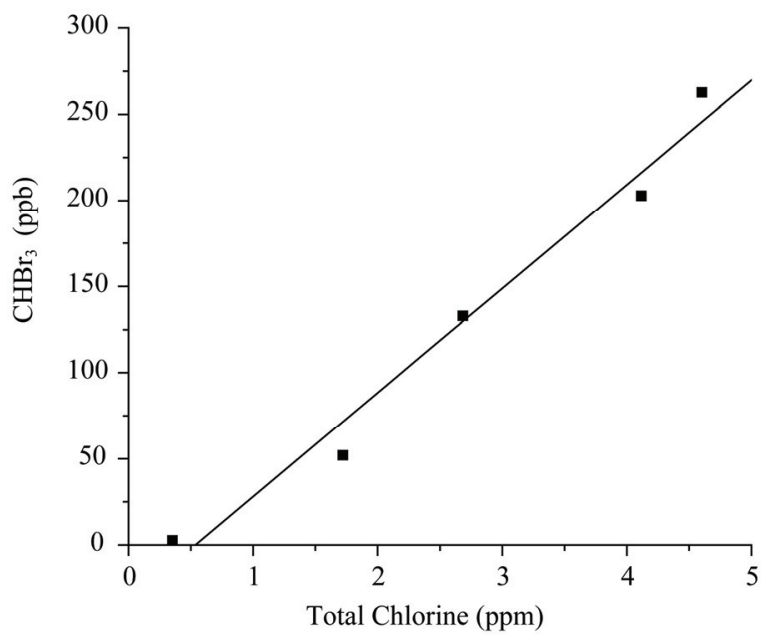

(b)

Figure 6. Evolution of final concentrations of (a) TTHMs and (b) bromoform as function total chlorine concentration during Doha seawater chlorination at room temperature $\left(25^{\circ} \mathrm{C}\right)$ and natural $\mathrm{pH}(\mathrm{pH}=8.3)$. $(-)$ fitting curve with OriginLab software.

lowing Equations (5)-(6):

$$
\begin{aligned}
& \mathrm{C}_{\text {tot }}(\mathrm{t})=\alpha+\beta \exp \left(-\mathrm{k}_{1} \mathrm{t}\right)+\gamma \exp \left(-\mathrm{k}_{2} \mathrm{t}\right) \\
& \mathrm{C}_{\text {Free }}(\mathrm{t})=\delta+\beta \exp \left(-\mathrm{k}_{3} \mathrm{t}\right)+\sigma \exp \left(-\mathrm{k}_{4} \mathrm{t}\right)
\end{aligned}
$$

The parameters $\alpha, \beta, \gamma, \delta, \sigma \mathrm{k}_{1}, \mathrm{k}_{2}, \mathrm{k}_{3}$ and $\mathrm{k}_{4}$ were determined using curve-fitting software. Values of these parameters and regression coefficient $\left(R^{2}\right)$, for each initial chlorine dose, are listed in Tables 3 and 4.

As it can be seen from Figure 7, parallel exponential first order decay functions exploited by the Origin software provided good fit with chlorine experimental data. The $\mathrm{R}^{2}$ values were close to 1 for both free and total chlorine concentrations. This model divided chlorine decay into two parts, fast reaction and slow reaction. Thus, it appears that parallel exponential first order decay is suitable for prediction of chlorine evolution with time during Doha seawater chlorination (up to 168 hours). This model is comparable to that proposed by Hass and Karra [20] for simulation of chlorine decay for filtered natural water.

Similar fitting method was used to predict the evolution with time TTHMs and bromoform concentrations. TTHMs and bromoform profiles can be also approximated using OriginLab curve-fitting software by Equations (7) and (8):

$$
\begin{aligned}
& {[\operatorname{TTHMs}(\mathrm{ppb})](\mathrm{t})=\mathrm{x}_{0}+\mathrm{A}_{1}\left[1-\exp \left(\frac{\mathrm{t}}{\mathrm{t}_{1}}\right)\right]} \\
& +\mathrm{A}_{2}\left[1-\exp \left(\frac{\mathrm{t}}{\mathrm{t}_{2}}\right)\right]
\end{aligned}
$$

$$
\begin{aligned}
& {\left[\mathrm{CHBr}_{3}(\mathrm{ppb})\right](\mathrm{t})=\mathrm{y}_{0}+\mathrm{A}_{3}\left[1-\exp \left(\frac{\mathrm{t}}{\mathrm{t}_{3}}\right)\right]} \\
& +\mathrm{A}_{4}\left[1-\exp \left(\frac{\mathrm{t}}{\mathrm{t}_{4}}\right)\right]
\end{aligned}
$$

Values of fitting parameters $\left(\mathrm{x}_{0}, \mathrm{y}_{0}, \mathrm{~A}_{1}, \mathrm{~A}_{2}, \mathrm{~A}_{3}, \mathrm{~A}_{4}, \mathrm{t}_{1}\right.$ and $t_{2}$ ) and regression coefficients for TTHMs and bromoform profiles are given in Tables 5 and 6, respectively. In addition, Figure 8 presents the evolution with time of both experimental and predicted (using Equations (7) and (8) and parameters from Tables 5 and 6) data for TTHMs and bromoform concentrations. As it can be observed predictive curves fit well experimental data for both TTHMs and $\mathrm{CHBr}_{3}$ concentrations; which is confirmed by regression coefficients $\left(\mathrm{R}^{2}\right)>0.98$.

Although OriginLab software gives excellent curvefitting results for chlorine decay and THMs formation during Doha seawater chlorination, the influence of many other parameters in seawater, including DOC content, natural organic matter, bromide concentration, $\mathrm{pH}$ and temperature, should be detailed. Therefore, further research is needed for modeling chlorine decay and THMs formation in seawater.

\section{Conclusions}

The main conclusions of this work can be summarized in the following points:

- Collected seawater was characterized by the presence of 0.35 ppm total chlorine, 6.64 ppm TOC, 64 ppm bromide and 1 ppb TTHMs. A rapid disappearance of chlorine, a decrease in UV absorbance 
Table 3. Parameters calculated by curve-fitting using OriginLab Origin 6.1 software of total chlorine concentration evolution with time during chlorination of Doha seawater with different chlorine dose at room temperature and natural pH.

\begin{tabular}{cccccccc}
\hline Chlorine dose & $\alpha$ & $\beta$ & $\gamma$ & $\mathrm{k}_{1}$ & $\mathrm{k}_{2}$ & $\mathrm{R}^{2}$ \\
\hline $1 \mathrm{ppm}$ & 0 & 1.29340 & 0.46870 & 1.055186 & 0.025026 & 0.988 \\
$2 \mathrm{ppm}$ & 0 & 0.61820 & 2.07768 & 2.080689 & 0.020918 & 0.982 \\
$3 \mathrm{ppm}$ & 0.331 & 1.92588 & 1.81310 & 0.269293 & 0.018558 & 0.985 \\
$4 \mathrm{ppm}$ & 0.646 & 0.99147 & 2.75343 & 0.057341 & 0.026583 & 0.991 \\
\hline
\end{tabular}

Table 4. Parameters calculated by curve-fitting using OriginLab Origin 6.1 software of free chlorine concentration evolution with time during chlorination of Doha seawater with different chlorine dose at room temperature and natural $\mathrm{pH}$.

\begin{tabular}{cccccc}
\hline Chlorine dose & $\delta$ & $\sigma$ & $\mathrm{k}_{3}$ & $\mathrm{k}_{4}$ & $\mathrm{R}^{2}$ \\
\hline $1 \mathrm{ppm}$ & 0.74435 & 0.29346 & 1.301744 & 0.036162 & 0.945 \\
$2 \mathrm{ppm}$ & 1.29342 & 0.46867 & 1.055045 & 0.025573 & 0.988 \\
$3 \mathrm{ppm}$ & 1.28489 & 1.29226 & 0.955393 & 0.023503 & 0.98156 \\
$4 \mathrm{ppm}$ & 1.40883 & 1.56595 & 1.008441 & 0.018031 & 0.97162 \\
\hline
\end{tabular}

Table 5. Parameters calculated by curve-fitting using OriginLab Origin 6.1 software of TTHMs concentration evolution with time during chlorination of Doha seawater with different chlorine dose at room temperature and natural $\mathrm{pH}$.

\begin{tabular}{ccccccc}
\hline Chlorine dose & $\mathrm{x}_{0}$ & $\mathrm{~A}_{1}$ & $\mathrm{~A}_{2}$ & $\mathrm{t}_{1}$ & $\mathrm{t}_{2}$ & $\mathrm{R}^{2}$ \\
\hline $1 \mathrm{ppm}$ & 1.02466 & 42.60321 & 19.77469 & 56.67088 & 0.32594 & 0.98132 \\
$2 \mathrm{ppm}$ & 0.98117 & 51.15133 & 52.80093 & 38.60196 & 0.2887 & 0.99698 \\
$3 \mathrm{ppm}$ & 1.38706 & 43.76408 & 89.17082 & 44.15398 & 0.38491 & 0.99262 \\
$4 \mathrm{ppm}$ & 0.93447 & 34.92287 & 34.67155 & 128.04165 & 0.32724 & 0.99744 \\
\hline
\end{tabular}

Table 6. Parameters calculated by curve-fitting using OriginLab Origin 6.1 software of $\mathrm{CHBr}_{3}$ concentration evolution with time during chlorination of Doha seawater with different chlorine dose at room temperature and natural $\mathrm{pH}$.

\begin{tabular}{ccccccc}
\hline Chlorine dose & $\mathrm{y}_{0}$ & $\mathrm{~A}_{3}$ & $\mathrm{~A}_{4}$ & $\mathrm{t}_{3}$ & $\mathrm{t}_{4}$ & $\mathrm{R}^{2}$ \\
\hline $1 \mathrm{ppm}$ & 1.41806 & 11.26989 & 39.28299 & 41.11591 & 0.35191 & 0.98132 \\
$2 \mathrm{ppm}$ & 1.787 & 20.29675 & 111.64617 & 37.08255 & 0.34555 & 0.99504 \\
$3 \mathrm{ppm}$ & 1.61331 & 33.15593 & 172.39088 & 29.90523 & 0.35355 & 0.99611 \\
$4 \mathrm{ppm}$ & 1.44775 & 42.15865 & 229.60479 & 21.72216 & 0.35191 & 0.98281 \\
\hline
\end{tabular}

and an increase of TTHMs concentration were observed during Doha seawater preservation at room temperature. THMs concentrations and speciation changed with time. Chloroform which is not detectable in raw seawater became the main THM component after 168 hours.

- Chlorination of Doha seawater with $1 \mathrm{ppm}$ chlorine dose led to increase in TTHMs concentration. Bromoform, chloroform, DBCM and BDCM were identified as chlorination by-products in Doha seawater with molecular fractions of 40.3, 31.4,
22.8 and $5.4 \%$, respectively. $\mathrm{CHBr}_{3}$ and $\mathrm{CHCl}_{3}$ have comparable molar concentrations which is indicative of competitive reaction of chlorine and bromine with natural organic matter in Doha seawater to form a mixture of chlorinated and brominated by-products.

- The results obtained have shown that chlorine dose has a significant influence on THMs concentrations and speciation. The increase of chlorine dose increased TTHMs and bromoform concentration, while bromoform, BDCM and DBCM concentra- 


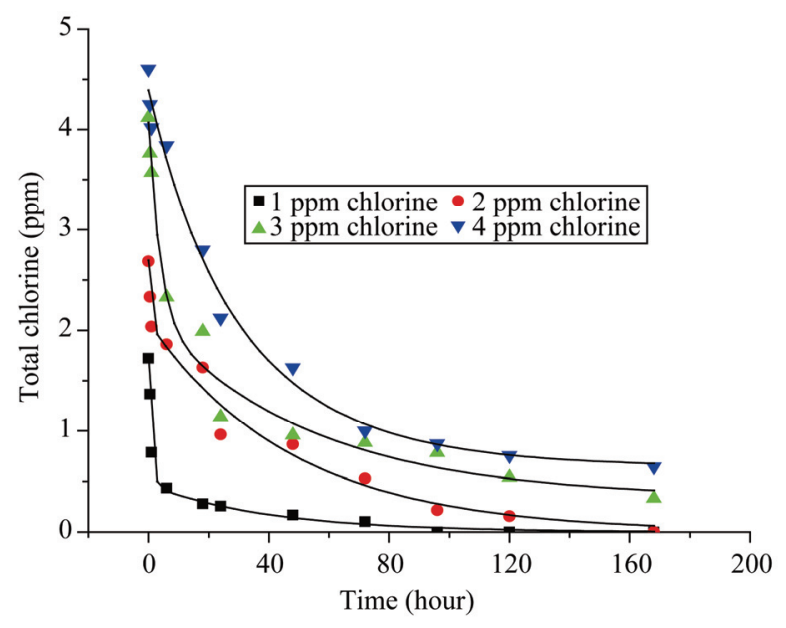

(a)

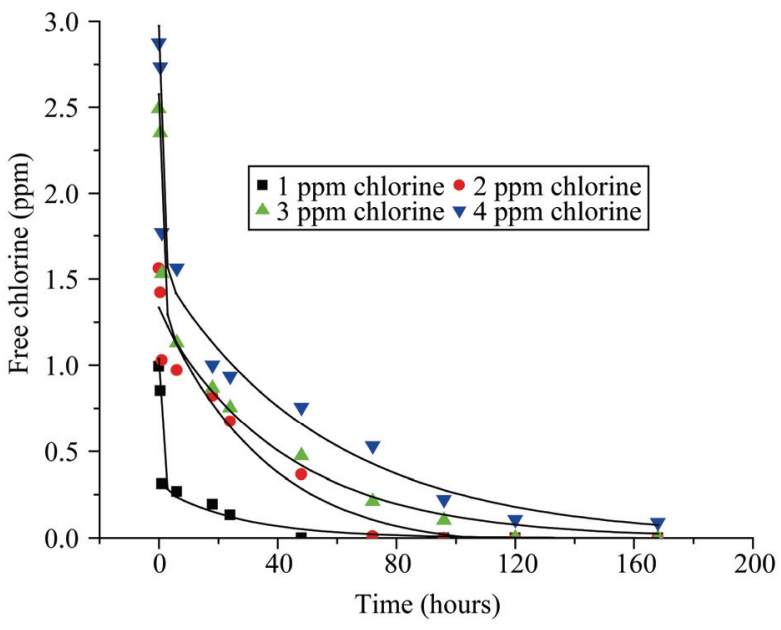

(b)

Figure 7. Fitting curves exploited from OriginLab software (lines) and experimental data (symbols) of (a) total chlorine and (b) free chlorine concentrations during Doha seawater chlorination with different chlorine doses at room temperature $\left(25^{\circ} \mathrm{C}\right)$ and natural $\mathrm{pH}(\mathrm{pH}=8.3)$.

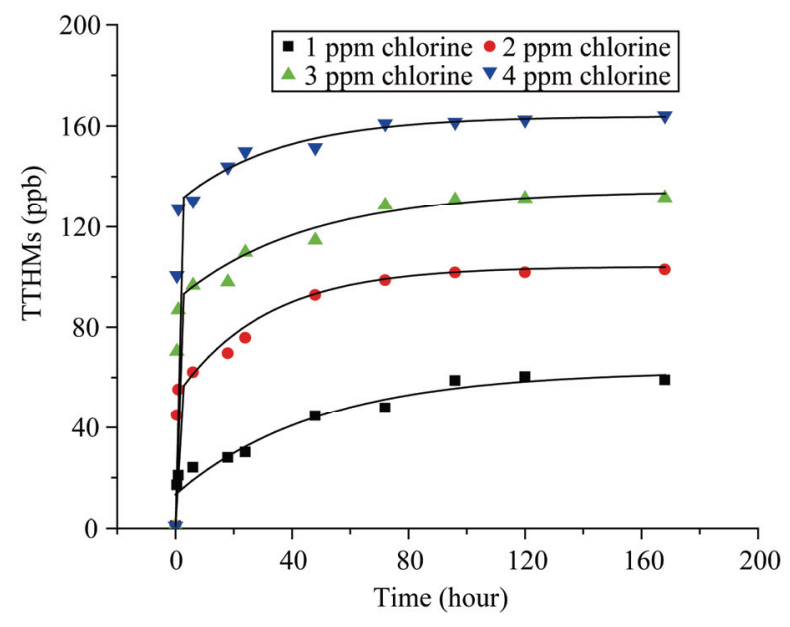

(a)

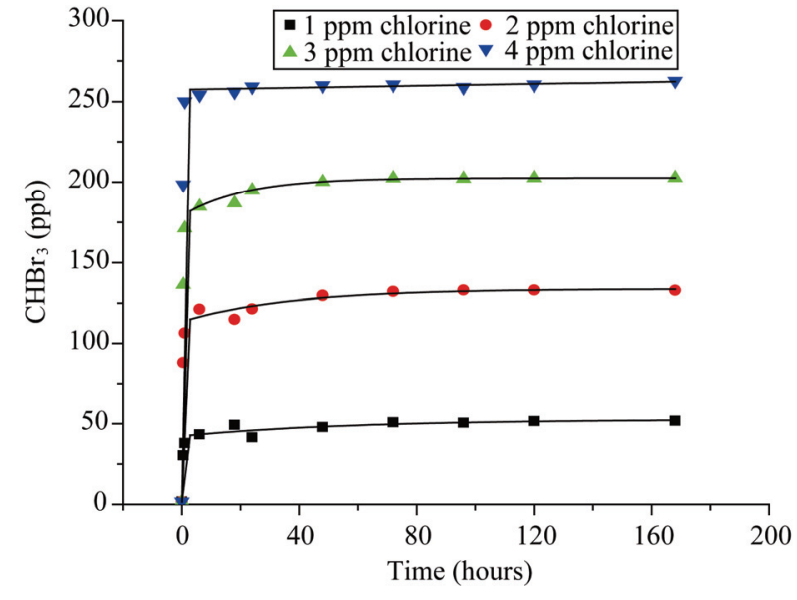

(b)

Figure 8. Fitting curves exploited from OriginLab software (lines) and experimental data (symbols) of (a) TTHMs and (b) bromoform concentrations during Doha seawater chlorination with different chlorine doses.

tions were almost invariant. Bromoform molar fraction was then increased to becoming the dominant THM component formed during seawater chlorination with chlorine dose increase. Linear behaviors were observed for TTHMs and bromoform concentrations with initial total chlorine concentration indicating good opportunity to control THMs formation to minimizing their environmental impacts.

- Curve-fitting method using OriginLab (Origin version 6.1) software was used to predict the evolution with time of total chlorine, free chlorine, TTHMs and bromoform concentrations during Doha sea- water chlorination with different chlorine doses. Parallel exponential first order decay functions exploited by the Origin software provided good fit with free and total chlorine experimental data, but exponential associate profiles was established for TTHMs and $\mathrm{CHBr}_{3}$ concentrations.

\section{Acknowledgement}

This research was supported by a research grant from the Qatar National Research Fund under its National Priority Research Program (NPRP). Its contents are solely the responsibility of the authors and do not necessarily represent the official views of the Qatar National Research 
Fund.

\section{REFERENCES}

[1] E. Agus, N. Voutchkov, D. L. Sedlak, "Disinfection Byproducts and Their Potential Impact on the Quality of Water Produced by Desalination Systems: A Literature Review," Desalination, Vol. 237, No. 54, 2009, pp. 214237.

[2] A. M. Shams El Din, A. A. Rasheed and A. A. Hammoud, "A Contribution to the Problem of Trihalomethane Formation from the Arabian Gulf Water," Desalination, Vol. 85, No. 1, pp. 13-32.

[3] M. Ali and P. Riley, "The Distribution of Halomethanes in the Coastal Waters of Kuwait," Marine Pollution Bulletin, Vol. 17, No. 9, 1986, pp. 409-414.

[4] B. Batchelor, "A Kinetic Model for Formation of Disinfection By-Products," Fellowship Report, American Academy for the Advancement of Science/Environmental Protection Agency Fellowship Program, Washington, DC, 1989.

[5] W. R. Haag and M. H. Lietzke, "A Kinetic Model for Predicting the Concentrations of Active Halogens Species in Chlorinated Saline Cooling Waters: A Final Report," ORNL/TM-7942, Oak Ridge National, 1981.

[6] J. D. Johnson, G.W. Inman and T. W. Trofe, "Cooling Water Chlorination: The Kinetics of Chlorine, Bromine, and Ammonia in Sea Water," NUREG/CR-1522 RE, Office of Nuclear Regulatory Research, U. S. Nuclear Regulatory Commission, Washington, DC, 1982.

[7] J. D. Johnson and R. Overby, "Bromine and Bromamine Disinfection Chemistry," Journal of Sanitary Energy Division, Vol. 97, No. 5, 1971, pp. 617-628.

[8] M. J. Rodriguez, J. B. Serodes, P. Levallois and F. Proulx, "Chlorinated Disinfection By-Products in Drinking Water According to Source, Treatment, Season, and Distribution Location," Journal of Environmental Engineering Science, Vol. 6, No. 4, 2007, pp. 355-365.

[9] USEPA, "Stage 2 Disinfectants and Disinfection Byproducts Rule," 2006.

[10] P. D. Goodman, "Effect of Chlorine on Materials for Sea Water Cooling Systems: A Review of Chemical Reactions," British Corrosion Journal, Vol. 70, No. 11, 1987, pp. 56-62.

[11] APHA, AWWA and WET, "Standard Methods for the Examination of Water and Wastewaters" 21st Edition, Washington, DC, 2005.

[12] M. Fabbricino and G. V. Korshin, "Formation of Disinfection By-Products and Applicability of Differential Absorbance Spectroscopy to Monitor Halogenation in Chlorinated Coastal and Deep Ocean Seawater," Vol. 176, No. 1-3, 2005, pp. 57-69.

[13] M. N. Fayad and S. Iqbal, "Chlorination Byproducts of Arabian Gulf Seawater," Bulletin of Environmental Contamination and Toxicology, Vol. 38, No. 3, 1987, pp. 475-482.

[14] G. L. Amy, P. A. Chadik and Z. K. Chowdhury, "Developing Models for Predicting Trihalomethane Formation Potential and Kinetics," Journal of American Water Works Association, Vol. 79, No. 7, 1987, pp. 89-97.

[15] D. Gang, T. E. Clevenger and S. K. Banerji, "Relationship of Chlorine Decay and THMs Formation to NOM size" Journal of Hazardous Materials, Vol. 96, No. 1, 2003, pp. 1-12.

[16] B. A. Engerholm and G. L. Amy, "A predictive Model for Chloroform Formation from Humic Acid," Journal of American Water Works Association, Vol. 75, No. 8, 1983, pp. 418-423; "chlorinated coastal and deep ocean seawater" Desalination, Vol. 176, No. 1-3, 2005, pp. 57-69.

[17] E. E. Chang, P. C. Chiang, S. H. Chao and Y. L. Lin, "Relationship between Chlorine Consumption and Chlorination By-Products Formation for Model Compounds," Chemosphere, Vol. 64, No. 7, 2006, pp. 11961203.

[18] J. Sohn, G. Amy, J. Choc, Y. Leed and Y. Yoon, "Disinfectant Decay and Disinfection By-Products Formation Model Development: Chlorination and Ozonation ByProducts," Water Research, Vol. 38, No. 10, 2004, pp. 2461-2478.

[19] C. N. Hass and S. M. Karra, "Kinetics of Wastewater Chlorine Demand Exertion," Journal of Water Pollution Control Federation, Vol. 56, No. 2, pp. 170-173.

[20] AWWARF, "Maintaining Distribution System Residuals through Booster Chlorination," AWWA Research Foundation, Denver, 2003. 